NASA Technical Memorandum 105165

AIAA-91-2121

\title{
Laser Interferometric Measurement of Ion Electrode Shape and Charge Exchange Erosion
}

Gregory S. MacRae and Carolyn R. Mercer

Lewis Research Center

Cleveland, Ohio

Prepared for the

27th Joint Propulsion Conference

cosponsored by AIAA, SAE, ASME, and ASEE

Sacramento, California, June 24-27, 1991 


\title{
LASER INTERFEROMETRIC MEASUREMENT OF ION ELECTRODE SHAPE AND CHARGE EXCHANGE EROSION
}

\author{
by \\ Gregory S. MacRae and Carolyn R. Mercer \\ National Aeronautics and Space Administration \\ Lewis Research Center \\ Cleveland $\mathrm{OH}$
}

\begin{abstract}
A novel, projected fringe profilometry system was applied to surface contour measurements of an accelerator electrode from an ion thruster. The system permitted non-contact, non-destructive evaluation of the fine and gross structure of the electrode. A three dimensional surface map of a dished electrode was generated without altering the electrode surface. The same system was used to examine charge exchange erosion pits near the periphery of the electrode to determine the depth, location, and volume of material lost. This electro-optical measurement system allowed rapid, non-destructive, digital data acquisition coupled with automated computer data-processing. In addition, variable sensitivity allowed both coarse and fine measurements of objects having various surface finishes.
\end{abstract}

\section{INTRODUCTION}

Ion extraction electrodes are the critical elements of an ion engine. The hole pattern and geometry establish the maximum beam current, the rate of neutral loss, and the limiting accelerating voltage. ${ }^{1,2}$ The shape of the electrodes and the mounting system determine the motion of the electrodes as they are thermally loaded. ${ }^{3}$ In addition, erosion of the electrodes may be the life limiting factor in an ion thruster., ${ }^{4,5}$ This paper describes a method of measuring both the gross initial shape of the electrodes and the fine structure of accelerator electrode erosion pits.

Currently, there is no simple method of measuring the initial shape of an electrode or charge exchange erosion pits. In the past, a shadow graph has been used to map the shape of the electrodes. This is an inherently two dimensional technique that is incapable of quantifying the size and depth of flat spots and regions of reversed concavity.

Erosion pits have been measured by several methods, including: examining reverse structures obtained using dental putty, measuring the position of the objective of a microscope focused alternately on the surface of the electrode and the bottom of a pit, ${ }^{6}$ sectioning the electrodes, ${ }^{4}$ and examination of erosion badges. ${ }^{7}$ Of these methods, only erosion badges provide three dimensional (3D) quantitative measurements with errors less than $50 \mu \mathrm{m}$. While erosion badges can provide extremely high accuracy, on the order of $0.06 \mu \mathrm{m}$ resolution, they have many shortcomings. Among these, (1) there are questions about the spalling rate of the badge material compared to the electrode material, (2) the inspection sites must be predetermined, (3) the badges introduce a change in the surface contour and consequent changes in the electric fields, and (4) they can only measure a small change in depth. These combine to make erosion badges unsuitable for long duration tests where interesting, single event phenomena can occur anywhere on the electrode and holes completely penetrating the accelerator electrode have been observed.

Various optical methods exits for measuring surface profiles of diffusely reflecting objects. Some methods, such as triangulation, ${ }^{8}$ differential scanning interferometry, phase locked interferometry, ${ }^{10}$ phase measurement interferometry, ${ }^{11}$ phase locked Moire topography, ${ }^{12}$ or holographic heterodyne interferometry ${ }^{13}$ require an individual measurement at each point on the surface of the object. Others provide full-field data acquisition to map the entire surface with only one or a few measurements required. These fullfield systems include phase-stepped shearing interferometry, ${ }^{14}$ phase-stepped projection Moire profilometry, ${ }^{15}$ sandwich holographic interferometry, ${ }^{16}$ two-wavelength, electronic speckle pattern interferometry, ${ }^{17}$ and Fourier transform profilometry. ${ }^{18}$ Of these methods, Moire techniques require accurately manufactured gratings which determine the measurement sensitivity, holographic techniques are extremely sensitive to environmental disturbances, speckle pattern techniques greatly limit the amount of available light, and shearing and open-loop phase-shift interferometry are subject to measurement errors based on phase-step miscalibration.

The laser measurement system described herein is a phase-shift profilometer that employs projected interference fringes and closed-loop phase control to provide variable surface height measurement resolution with reduced sensitivity to environmental disturbances. ${ }^{19}$. The system is nondestructive, non-contacting, and permits variable depth accuracy to accommodate objects of different sizes. Accuracies were evaluated for each measurement region, and tolerance for surface discoloration, holes, and specular 
reflections was demonstrated. In addition, the initial shape contours for the electrode are compared to a computed spherical surface, and the erosion pit contours are measured and integrated to obtain the volumetric losses as a function of the radial location of the pit.

\section{APPARATUS}

Two beams from an argon ion laser were used to illuminate an accelerator electrode. Four images of the electrode were recorded, with the relative phase of the two beams stepped between each exposure. A desk top computer was used to drive the phase controller and to digitize the images. The images were then transferred to a mainframe computer to compute the surface profile. The measurement system and the electrode under study are both described in detail below.

\section{Projected Fringe Interferometer}

The projected fringe interferometer is shown schematically in Fig. 1. The beam from a 1.2 Watt argon ion laser operating at $514 \mathrm{~nm}$ is passed through an opto-isolator to guard against the effects of back scattered light, and coupled to a single mode, non-polarization preserving, optical fiber $\left(\mathrm{F}_{\text {in }}\right)$ using a convergent lens system $\left(L_{1}\right)$. The light is split using a 50-50 fiber coupler (FC) to provide light of equal intensity from two fiber ends $\left(F_{1}\right.$ and $\left.F_{2}\right)$. Each fiber is tightly wrapped around separate piezoelectric cylinders (PZT 1 and PZT $_{2}$ ), and the polarization state of the two beams is controlled by birefringence. The two beams are recombined using a 50-50 beam splitting cube, creating two interference fringe patterns. One fringe pattern is selected for use, filtered through a polarizer (PF), and collimated using either a lens $\left(L_{2}\right)$ or a mirror (not shown). The other beam is blocked off.

Some light in the fibers is internally reflected at the fiber faces, and recombines in the fiber labeled $F_{\text {our }}$. The intensity of this light varies as $\sin 2 \theta$, where $\theta$ is the phase difference between the light at the fiber faces. The intensity is metered by a photodiode (PD) and used as input for the phase controller (PHASE CONTROLLER). The phase controller modulates the detected signal by supplying a high frequency, low amplitude, sinusoidal voltage to $P^{2} T_{1}$. A voltage proportional to $\theta$ is produced by multiplying the detected signal by the modulation frequency and then lowpass filtering the result. The phase control loop is closed by applying this voltage to $\mathrm{PZT}_{2}$, altering the phase of the light travelling through $F_{2}$ until $\theta$ is stabilized. An open loop voltage is applied to $\mathrm{PZT}_{2}$ to coarsely set the desired phase. The phase difference, $\theta$, is fine tuned to multiples of $\pi / 2$ by manipulating the polarity of the multiplier in the phase controller. ${ }^{20}$

The collimated beams from the output fibers are used to illuminate the object under study. The interference pattern appears as alternating bright and dark fringes on the surface of the object. The pattern is translated by one quarter of a cycle with each $\pi / 2$ radian phase step. An image of the object illuminated by this interference pattern is digitized using a solid state camera after each phase step. The four images are stored for later processing to compute the surface profile of the object.

\section{Ion Engine Electrode}

The accelerator electrode used was tested more than 5800 hours in ion engines using mercury and xenon propellants. ${ }^{5,21}$ The electrode is made of $580 \pm 30 \mu \mathrm{m}$ thick molybdenum sheet that has been dished to a lenticular shape and chemically etched to provide ion extraction holes. Most of the surface was dull, bare metal, with many speculgrly reflective facets. It showed signs of ion machining, and portions were variously painted and marked to provide references for other tests. For these tests, a large band along a diameter was painted white to provide a diffusively reflecting surface for image comparisons. The electrode was dished to a nominally spherical surface with a $29.4 \mathrm{~cm}$ chord and a depth of $2.22 \mathrm{~cm} .^{1}$ It was perforated with nominally circular holes $1.52 \mathrm{~mm}$ in diameter in a hexagonal pattern with $2.21 \mathrm{~mm}$ centers and $0.4 \%$ compensation to provide beamlet steering. ${ }^{22}$ The compensation factor increased the center to center spacing by 0.004 times the radial location of the hole to compensate for the effects of dishing the electrode. The actual hole diameters varied due to erosion from ion impingement.

As noted above, this electrode experienced extencled testing in both mercury and xenon ion engines. Some of these tests led to the recognition of the severe erosion problems associated with operating a high power, xerion thruster in a high back pressure $\left(2 \times 10^{-3} \mathrm{~Pa}\right)$ vacuum system ${ }^{5}$. More than half the erosion pits extended completely through the electrode.

\section{THEORY}

The projected fringe profilometer produces interference fringes that illuminate the electrode. The intensity at any given point on the electrode is a function of the average laser intensity; the relative phase $(\theta)$ of the light at the output fiber faces; and the surface height of the electrode. Variation in the fringe pattern caused by variations in surface height can be extracted by recording the intensity 
pattern four times with $\theta$ stepped by precisely $\pi / 2$ radian between exposures and using the formula:

$$
\tan \Psi_{x, y}=\frac{I 4_{x, y}-I 2_{x, y}}{I I_{x, y}-I 3_{x, y}}
$$

where $\Psi_{x, y}$ is the relative phase at the pixel location $(x, y)$ and $\operatorname{In}_{x, y}$ is the intensity at pixel $(x, y)$ in image $n$.

The carrier phase pattern of the interference fringes can be removed by subtracting the relative phase pattern of a computed reference surface from the phase pattern generated for the object. This reference surface is a flat plane with a slope given by,

$$
m=\frac{2 \pi}{\lambda_{f}} \sin \alpha,
$$

where $m$ is the slope, $\lambda_{\mathrm{f}}$ is the fringe wavelength, and $\alpha$ is the angle of incidence of the collimated beam on the reference flat (Fig. 2). The resultant phase map, $\Delta \Psi$, is proportional to the surface map of the electrode. The constant of proportionality depends on the fringe spacing and position of the electrode relative to both the collimated illumination beam and the camera according to the formula:

$$
h_{x, y}=\frac{\Delta \Psi_{x, y}}{2 \pi} \frac{\lambda_{f}}{\cos \alpha}
$$

where $h_{x, y}$ is the height at pixel $(x, y), \Delta \Psi_{x, y}$ is the phase at pixel $(x, y)$, with the other variables defined above.

The fringe wavelength can be varied by adjusting the position of the ends of the fibers or changing the point where the beam is collimated. This control permits variations in the resolution as required by the size of the object or region of the object being imaged. Shorter wavelengths permit higher resolutions up to the spatial resolution limit for the camera to distinguish the light intensity variations. Decreasing the incidence angle between the object and the beam increases the resolution up to the limit where the object casts shadows on itself.

\section{EXPERIMENTAL PROCEDURE}

The experimental procedure can be broken into several steps: alignment of the laser optical system, determination of the object's position, imaging of the object, and the data processing. The alignment of the laser system, creation of the interference pattern, and the phase stepping of the pattern are described above and will not be repeated here.
The position of the object is somewhat arbitrary, however, the incidence angle and fringe spacing should be selected to obtain an appropriate measuring sensitivity. To determine the reference angle, the collimated beam was aligned with a reference line on the laser table, and the angle between the object and the line was measured. The fringe wavelength was found by imaging a ruler and examining the phase map to determine the fringe spacing.

For maximum resolution, the camera should view the object perpendicularly to the surface. This provides the best focus and minimum foreshortening. While imaging the whole electrode, camera placement was straightforward. Imaging the erosion pits, however, necessitated placing the lens very close to the surface of the electrode, so the camera had to be mounted at an angle to preclude casting a lens shadow across the imaged region. Consequentially, the image is foreshortened and both sides are noisy and out of focus (Fig. 3). The foreshortening can be accommodated by scaling the vertical and horizontal dimensions separately.

Specular reflections off the metal electrode, especially near the steep erosion pit walls, proved to be the most challenging aspect of imaging the electrode. The bright specular reflections caused data loss not only in the area of the reflection, but also along many adjacent pixels because of saturation blooming. This effect was removed by using a charge injection device (CID) camera rather than a charge coupled device (CCD) camera. The limited dynamic range of the data acquisition system, approximately $100: 1$, still caused saturation at the specular regions, but the blooming was eliminated. A second challenge was to image deep erosion pits. Matte white paint was sprayed on the electrode to increase the reflectivity of the surface. The paint was assumed to have a uniform thickness. This allowed imaging some pits with holes completely penetrating the electrode. Near the center of the electrode, where the erosion was most severe, the eroded surface was too steep to illuminate completely and the pits could not be accurately contoured.

The contouring system is sensitive to motion on the order of $\lambda_{f} / 100$. To minimize vibration, the fringe interferometer and electrode were moùnted on a vibration isolation table. For the close-up images of the erosion pits, the camera was mounted on the same table, for the whole electrode images, the camera was mounted on a tripod separate from the optical table.

A desktop computer controlled the phase stepping of the fringes and image acquisition. All four images were collected in less than 30 seconds. The images were then uploaded to a mainframe for further processing. A phase map of the object was computed using Eq. (1). A plane with a slope defined by Eq. (2) was subtracted from the object phase map to generate a differential phase map. The phase map is computed modulo $2 \pi$, but the object had 
surface height variations greater than the height corresponding to a $2 \pi$ differential phase. As a result, the differential phase map had to be processed to eliminate 0 to $2 \pi$ discontinuities. This "unwrapped" phase map was multiplied by a conversion factor, determined using Eq. (3), to obtain the measured surface contour.

Where there were holes in the imaged object, the computed contour is meaningless. To mask these areas, the holes are located by summing all four image frames and making a binary map of all the points with total intensities greater than a selected threshold value. Speckle noise caused by laser illumination was reduced by applying a median filter to the contour map, followed by pixel averaging. A filtered, thresholded surface is shown in Fig. 4 for the entire electrode.

\section{Error Sources}

Sources of error in the surface profile measurement arise from uncertainties in the measurements of $\alpha$ and $\lambda_{i} ;$ errors in $\theta$; dark current and shot noise in the camera; laser intensity and polarization fluctuations; and mechanical vibration between the electrode, camera, and output fiber faces. The laser intensity was actively stabilized, and the polarization was assumed to be stable during the short time required to acquire four images. A vibration isolation table with rigid mounting was employed to minimize mechanical vibration. The phase controller was stable to within $0.4^{\circ} .^{20}$ Using a flat, white surface, a $12^{\circ}$ minimum phase uncertainty was measured. An uncertainty in $\alpha$ of $1.0^{\circ}$, and a fringe wavelength uncertainty of about $0.3 \%$ produces an uncertainty of $3.3 \%$, or $4 \mu \mathrm{m}$ for the pit measurements. However, where the object has poor reflectivity or unfavorable reflection angles, the peak signal strength is reduced and the uncertainty is greater. Again for the pit measurements, phase error ranged from $20^{\circ}$ in the brightest regions, to $56^{\circ}$ in the darker areas, corresponding to 10 to $25 \mu \mathrm{m}$ uncertainty for the electrode pit measurements.

\section{RESULTS AND DISCUSSION}

Large and small scale measurements of the electrode were made using a projected fringe profilometer. The specific measurements are described below.

\section{Electrode Shape Measurements}

The gross shape of the electrode influences the thermal response of the electrode, and determines the amount of compensation required to produce a collimated ion beam. Many thermomechanical analyses of the electrodes have been conducted to find the response function. ${ }^{323-25}$ All of these analyses have assumed an initial shape for the electrode without measuring the actual shape. Most have assumed that the dished electrodes have a spherical section shape. Hole alignment compensation is also based upon an assumed spherical shape. When the surface is spherical, a linear adjustment to the radial location of the holes on the accelerator can compensate for hole misalignments and provide beamlet steering to control the beam focus. The surface of the electrode was contoured and compared to a computed spherical surface (Fig. 4). The measurement uncertainty was $2 \mathrm{~mm}$. A sphere of $49.8 \mathrm{~cm}$ radius provided a very good fit, with no deviations greater than $4.7 \mathrm{~mm}$. As shown in Fig. 5, the measurable deviations occur only at the edge of the electrode. The fact that one edge appears high while the other appears low may be due to some residual tilt in the image.

Also of interest are local shape anomalies. In unpublished work, Brophy showed that small electrode surface shape anomalies can have a significant impact on the thermal response. ${ }^{26}$ The analysis was conducted by assuming possible shapes of the anomalies. No shape anomalies with depths greater than the measurement uncertainty of 2 $\mathrm{mm}$ were found (Fig. 5).

The relative insensitivity of projected fringe contouring to small vibrations led to the consideration of using it to measure thermally induced deflections. Unfortunately, the maximum out-of-plane deflections observed are on the order of $0.5 \mathrm{~mm},{ }^{27}$ which is less than the resolution limit of the projected fringe system when the whole electrode is imaged. Unless camera resolutions can be improved by an order of magnitude or more, projected-fringe contouring can contribute little to the measurement of thermally induced displacements.

\section{Charge Exchange Erosion Measurements}

During normal operation of a two electrode ion engine, small pits are ion etched into the accelerator electrode. The mechanism for this erosion is charge exchange between beam ions and slow moving neutral ions near the electrcide which produces slow moving ions that are attracted to the negatively charged outer electrode. The local electric field focuses the charge exchange ions into the region between the extraction holes. The typical erosion pattern is a hexagonal groove approximately centered on each hole (Fig. 6). The midpoint of the leg is a saddle point with progressively less erosion in the direction of the nearest hole, and more erosion progressing from the midpoint to the corners where the deepest erosion occurs. Electrodes which have been operated for long times, including the electrode examined in this paper, can be eroded completely through the corner pit regions. 
Across small areas, good depth resolution can be attained by decreasing the fringe wavelength used with the projected-fringe interferometer. This permits contouring of the charge exchange pits on the accelerator electrode of two electrode ion engines. The relatively shallow erosion pits around the edge of the electrode were readily imaged and required no changes to the electrode surface. Shadows and poor reflection angles prevented contouring of the deepest erosion pits, even when the surface was painted white. It was possible, however, to obtain contours of pits near the radius where holes are first observed. Two lens systems were used to image the charge exchange pits. The data shown were all taken with a $55 \mathrm{~mm}$ focal length lens at $\mathrm{f} / 4$ used with a $125 \mathrm{~mm}$ extension tube and positioned about 3 $\mathrm{cm}$ from the surface of the electrode. At a distance of 1.2 $\mathrm{m}$, it was possible to image the surface using a close-up, Cassegrain lens, but the image covered four times the area and was too dark to allow use of a camera that did not have a controllable, variable exposure time.

Seven pairs of pits on the electrode were contoured. Extraction holes, located as shown in Fig. 7, are contoured in a sequence of six images (Figs. 8-13) in order to examine the change in location and depth of the pits. One pit pair within $5 \mathrm{~cm}$ of the electrode center was examined, but could not be contoured. The erosion at this location was very severe, completely penetrating the electrode. The sides of the eroded hole were too steep for the projected fringe technique, and shadows precluded making any useful measurements. The seventh pit pair (Fig. 14) was chosen to see if holes completely through the electrode could be imaged at all. Located $8.8 \mathrm{~cm}$ from the center of the electrode, the seventh pair was on the third row of pits from the edge that displayed erosion holes.

Beyond hole $\mathrm{H}_{1}$ (Fig. 8), at the edge of the electrode, the erosion is shallow and without any clearly discernable pattern. The deepest region is toward the electrode center, between three holes. This pattern is unique to the outer holes, much shallower than the other erosion, and will not be examined in detail. The deepest erosion near hole $\mathrm{H}_{1}$ extended $45 \mu \mathrm{m}$ down and occurred about midway between $\mathrm{H}_{1}$ and one of the outer holes. Integrating a section including this pit, the center of $\mathrm{H}_{1}$ and the centers of the two neighboring edge holes showed that $30 \mathrm{~mm}^{3}$ of material was eroded in this region (Table I).

The other six erosion regions that were contoured display the more characteristic hexagonal pattern. The pattern is first distinguishable around the third hole in from the edge, $\mathrm{H}_{2}$ (Fig. 9). The depth of the outermost pit near each hole and the depth of the outermost mid-leg, as indicated in Fig. 6, are reported in Table I. Table I also lists the volume of material eroded from each pit. This was found by integrating across a triangular section as was done with hole $\mathrm{H}_{1}$. The pit depths increased monotonically from $115 \mu \mathrm{m}$ near $\mathrm{H}_{2}$ to $420 \mu \mathrm{m}$ near $\mathrm{H}_{6}$. The erosion volumes also increase monotonically towards the center, from 40 to $89 \mathrm{~mm}^{3}$. The mid-leg depth increases toward the center of the electrode except near hole $\mathrm{H}_{3}$, where the groove is unusually deep, $65 \mu \mathrm{m}$. No explanation for the increased erosion was found.

The general increase in the severity of the erosion toward the electrode center was discernable to the naked eye. The erosion pattern near hole $\mathrm{H}_{7}$ displayed one of the outermost pits that extended completely through the electrode. A hole of approximately $6900 \mu^{2}$ is visible in the contour plot in Fig. 14. The erosion on the downstream surface of the electrode is the same hexagonal pattern described above, except that it is not centered on the holes. The groove is $112 \mu \mathrm{m}$ deep at the mid-leg of the hexagon and completely penetrates the electrode in the pit, as shown in Table $\mathbf{I}$. It is significant that the erosion near hole $\mathbf{H}_{7}$ penetrates the electrode without exceeding the initial half thickness at the mid-leg point, because erosion to a depth of half the initial thickness is used as the definition of end-oflife for the accelerator electrode. ${ }^{28}$ The hole has a triangular chamfer leading to a nearly circular orifice of approximately $47 \mu \mathrm{m}$ diameter. Integration across the charge exchange hole reveals that $75.8 \mathrm{~mm}^{3}$ of molybdenum has been eroded in this pit. Because these pits are only $4 \mathrm{~cm}$ closer to the center than the pits in Fig. 12, one can assume that the displacement of the erosion pattern is not due to the radial location. Rather, the pattern misalignment is probabily due to hole misalignment and the resultant beamlet steering. Note that the seventh hole is located on the opposite side of the electrode from the first six (Fig. 7).

The projected fringe profilometer was able to contour all of erosion pits that did not completely penetrate the electrode, and some that did. Measurement uncertainties were less than $25 \mu \mathrm{m}$ for all of the measurements. However, the suitability of the system for in-situ measurements remains unknown. Because four images, with known phase steps, are needed to produce a contour, the system is sensitive to motion perpendicular to the beam. This sensitivity can be ameliorated by using long fringe wavelengths and accepting a reduced depth resolution. Further testing is needed to define the uncertainties that can be obtained in-situ.

\section{Quality Control Measurements}

There are two areas of quality control that can benefit immediately from contour measurements, examination of flat, molybdenum sheets, and examination of the patterned and dished electrodes. Although there are specifications for acceptable ripple in the molybdenum sheet that will be processed into ion extraction electrodes, there is no specified 
method of measuring the ripple. A straightforward application for fringe interferometric contouring is examination of a nominally flat surface for deviations. The electrodes are currently dished hydrostatically to their lenticular shape. To optimize performance, the two or three electrodes must be the same shape and free of flat spots and areas of reversed curvature. Currently, the shape can only be measured after the electrodes have been chemically etched to create extraction holes. With holes, they can be stacked upon each other inspected manually. Using projected fringe contouring, the process can be automated and conducted prior to etching the holes. The procedure would be comparable to the electrode shape measurements described above. Sets that do not meet specifications could be culled before etching.

\section{CONCLUSIONS}

A projected-fringe profilometer was used to measure 3D, large and small scale contours of an ion thruster accelerator electrode. The measurements demonstrated the systems tolerance for the speckle and surface color variations across the electrode. The large scale measurements showed that the electrode was spherical in shape with no discernable shape anomalies. The small scale measurements showed the erosion due to charge exchange impingement. Erosion pits more than half way through the electrode were contoured with no surface finish changes required. A pit completely through the electrode was contoured after the surface was painted white. Shadows prevented contouring of some of the large erosion holes with very steep sides.

Large scale contouring of ion thruster electrodes can potentially impact design, analysis, and quality control procedures. Accurate shape contours may enable refinement of the hole pattern to improve ion extraction, especially with non-spherical electrode designs. Measurement of shape anomalies will help quantify their impact on performance, and define the relative importance shape and hole alignment play in limiting the perveance. Measurements of the initial shape can provide input for future structural analyses. Additionally, shape measurements performed before acceptance of the flat sheet stock and between dishing and etching the electrodes can be incorporated in quality control procedures. With current camera resolutions, the profilometry system is not suitable for thermally induced motion measurements, however. The measurement uncertainty of $2 \mathrm{~mm}$ is too large to resolve thermally induced motion that occurs during ion thruster operation.

Small scale contouring of the accelerator electrode can provide documentation of charge exchange erosion during long duration tests. Such measurements would be most useful if they could be conducted in-situ. Further testing is necessary to determine the feasibility of in-situ measurements; vibration may preclude such application.

\section{REFERENCES}

1. Rawlin, V. K., Banks, B. A., and Byers, D. C., "Dished Accelerator Grids on a 30-cm Ion Thruster," Journall of Spacecraft and Rockets, No. 1, Vol. 10, Jan. 1973, pp. 29-35.

2. Rawlin, V. K., "Sensitivity of 30-cm Mercury Bombardment Ion Thruster Characteristics to Accelerator Girid Design," AIAA Paper 78-668, April, 1978.

3. MacRae, G. S. and Hering, G. T., "Status of Structural Analysis of $30 \mathrm{~cm}$ Diameter Ion Optics," AIAA Paper 90-2649, July 1990.

4. Collett, C., "Fabrication and Verification Testing of ETM $30 \mathrm{~cm}$ Diameter Ion Thrusters," NASA CR135193, April 1977.

5. Rawlin, V. K., "Internal Erosion of a 10-kW Xenon Ion Thruster," AIAA Paper 88-2912, July 1988.

6. Patterson, M., "Performance and Optimization of a 'Derated' Ion Thruster for NSSK," AIAA Paper 912350, June 1991.

7. Beattie, J. R., "Endurance Test of a 30-cm Diameter Engineering Model Ion Thruster: Task XII-Investigation of Thin-Film Erosion Monitors for Ion Thrusters," NASA CR-168132, May 1983.

8. Cheng, X. X., Su, X. Y., and Guo, L. R., "Automated Measurement Method for 360 Profilometry of 3D Diffuse Objects," Applied Optics, No. 30, Vol. 10, 1991, p. 1274.

9. Bristow, T. C., Bouzid, A., and Bietry, J., "Surface Measurements and Applications for Manufactured Parts Using Non-contact Profilometer," Proceedings of SFIE, No. 954,1988 , p. 217.

10. Mathews, H. J., Hamilton, D. K., and Sheppard, C. J. R., "Surface Profiling by Phase-Locked Interferometry," Applied Optics, No. 25, Vol. 14, 1986, p. 2372.

11. Wyant, J. C. and Prettyjohns, K. N., "Three-Dimensional Surface Metrology Using a Computer-Controlled Noncontact Instrument," Proceedings of SPIE, No. 661, 1986, p. 292. 
12. Moore, D. T. and Truax, B. E., "Phase-Locked Moire Fringe Analysis for Automated Contouring of Diffuse Surfaces," Applied Optics, No. 18, Vol. 1, 1979, p. 91.

13. Dandliker, R. Ineichen, B., and Mottier, F. M., "High Resolution Hologram Interferometry by Electronic Phase Measurement," Optics Communications No. 9, Vol. 4, 1973 , p. 412.

14. Srinivasan, V., Liu, H. C., and Halioua, M., "Automated Phase Measuring Profilometry of 3D Diffuse Objects," Applied Optics, No. 23, Vol. 18, 1984, p. 3105.

15. Halioua, M., Krishnamurthy, R. S., Liu, H. C., and Chiang, F. P., "Automated 360 Degree Profilometry of 3D Diffuse Objects," Applied Optics, No. 24, Vol. 14, 1985 , p. 2193.

16. Abramson, N., "Sandwich Hologram Interferometry 3: Contouring," Applied Optics, No. 15, Vol. 1, 1976, p. 200.

17. Jones, R. and Wykes, C., Holographic and Speckle Interferometry, Cambridge University Press, 1983, p. 198.

18. Takeda, M. and Mutoh, K., "Fourier Transform Profilometry for the Automatic Measurement of 3D Object Shapes," Applied Optics, No. 22, Vol. 24, 1983, p. 3877.

19. Mercer, C. R. and Beheim, G., "Fiber-Optic ProjectedFringe Digital Interferometry," NASA TM-103252, November 1990.

20. Mercer, C. R. and Beheim, G., "Fiber Optic Phase Stepping System for Interferometry", Applied Optics, No. 30, Vol. 7, p. 729, 1991.

21. Mantenieks, M. A. and Rawlin, V. K., "Sputtering Phenomena of Discharge Chamber Components in a 30cm Diameter Hg Ion Thruster," AIAA Paper 76-400, Nov. 1976.

22. Danilowicz, R. L., Rawlin, V. K., Banks, B. A., and Wintucky, E. G., "Measurement of Beam Divergence of 30-cm Dished Grids," AIAA Paper 73-1051, Oct. 1973.

23. Poeschel, R. L. and Kami, S., "Analysis and Design of Ion Thrusters for Large Spacecraft Systems," NASA CR-165140, September 1980.
24. James, E. L., et al, "Advanced Inert Gas Ion Thrusters," NASA CR-161892, July 1984.

25. Brophy, J. R. and Aston, G., "Thermal Mechanical Analysis of Large Diameter Ion Accelerator Systems," AIAA Paper 89-2718, July 1989.

26. Brophy, J. R., private communications, 1990.

27. MacRae, G. S., Zavesky, R. J., and Gooder, S. T., "Structural and Thermal Response of $30 \mathrm{~cm}$ Diameter Ion Thruster Optics," AIAA Paper 89-2719, July 1989.

28. Patterson, M. J. and Foster, J. E., "Performance and Optimization of a 'Derated' Ion Thruster for Auxiliary Propulsion," AIAA Paper 91-2350, June 1991. 


\begin{tabular}{||c|cccc||}
\hline \multicolumn{4}{|c|}{ TABLE I. - CHARGE EXCHANGE EROSION MEASUREMENTS. } \\
\hline \hline $\begin{array}{c}\text { Nearest Hole } \\
\text { (Fig. 7) }\end{array}$ & $\begin{array}{c}\text { Figure } \\
\text { Number }\end{array}$ & $\begin{array}{c}\text { Pit Depth } \\
(\mu \mathrm{m} \pm 20)\end{array}$ & $\begin{array}{c}\text { Mid-Leg Depth } \\
(\mu \mathrm{m} \pm 10)\end{array}$ & $\begin{array}{c}\text { Volume Lost } \\
\left(\mathrm{mm}^{3} \pm 0.5\right)\end{array}$ \\
\hline $\mathrm{H}_{1}$ & 8 & 45 & 4 & 31.2 \\
$\mathrm{H}_{2}$ & 9 & 115 & 40 & 55.6 \\
$\mathrm{H}_{3}$ & 10 & 255 & 65 & 68.5 \\
$\mathrm{H}_{4}$ & 11 & 285 & 50 & 70.9 \\
$\mathrm{H}_{5}$ & 12 & 330 & 55 & 88.8 \\
$\mathrm{H}_{6}$ & 13 & 420 & 70 & 89.3 \\
$\mathrm{H}_{7}$ & 14 & 580 & 110 & 75.8 \\
\hline \hline a There is no discernable groove or mid-leg saddle point near hole $\mathrm{H}_{1}$. \\
\hline
\end{tabular}

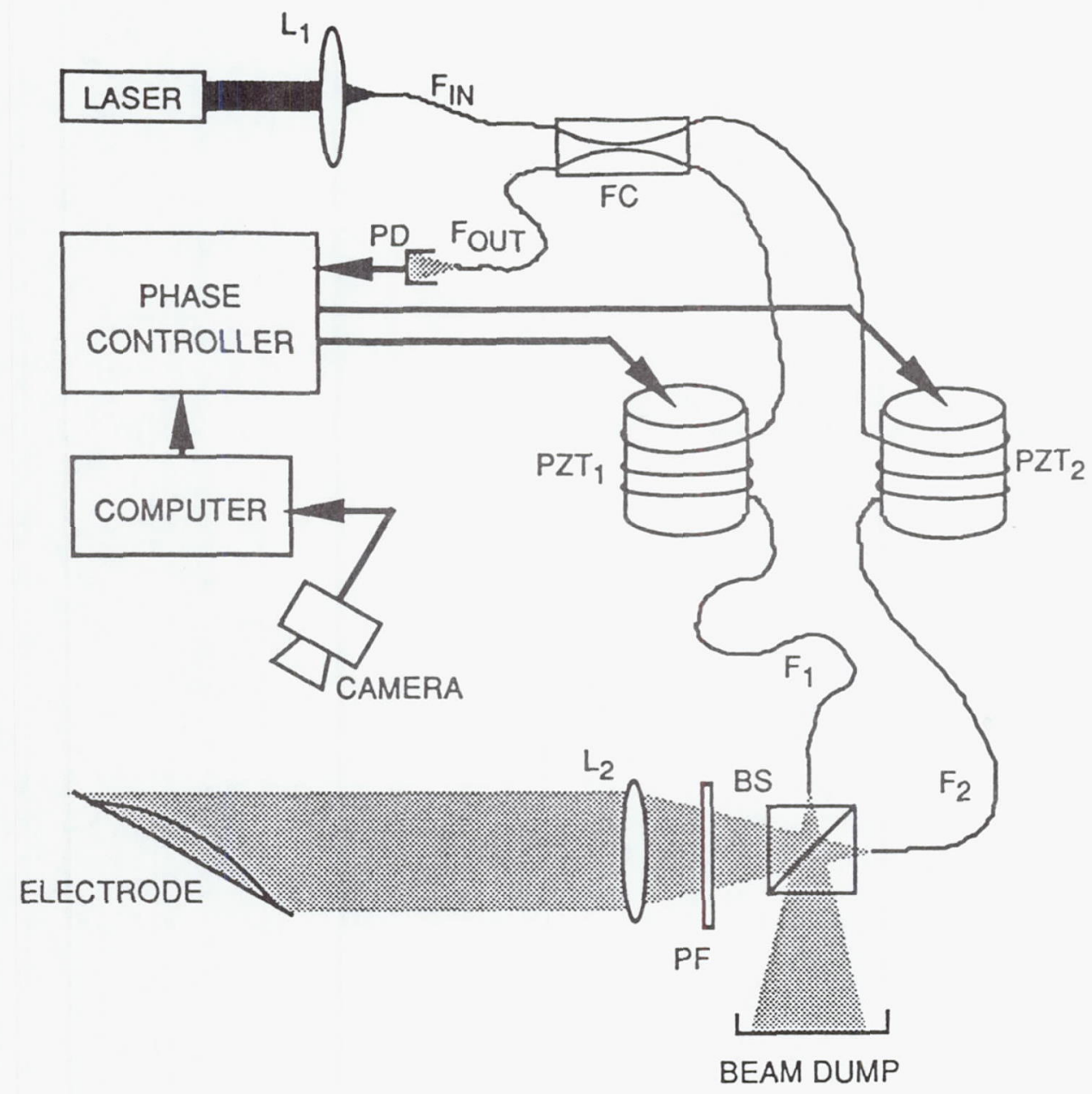

Figure 1. - Phase-stepped, projected fringe profilometer. 


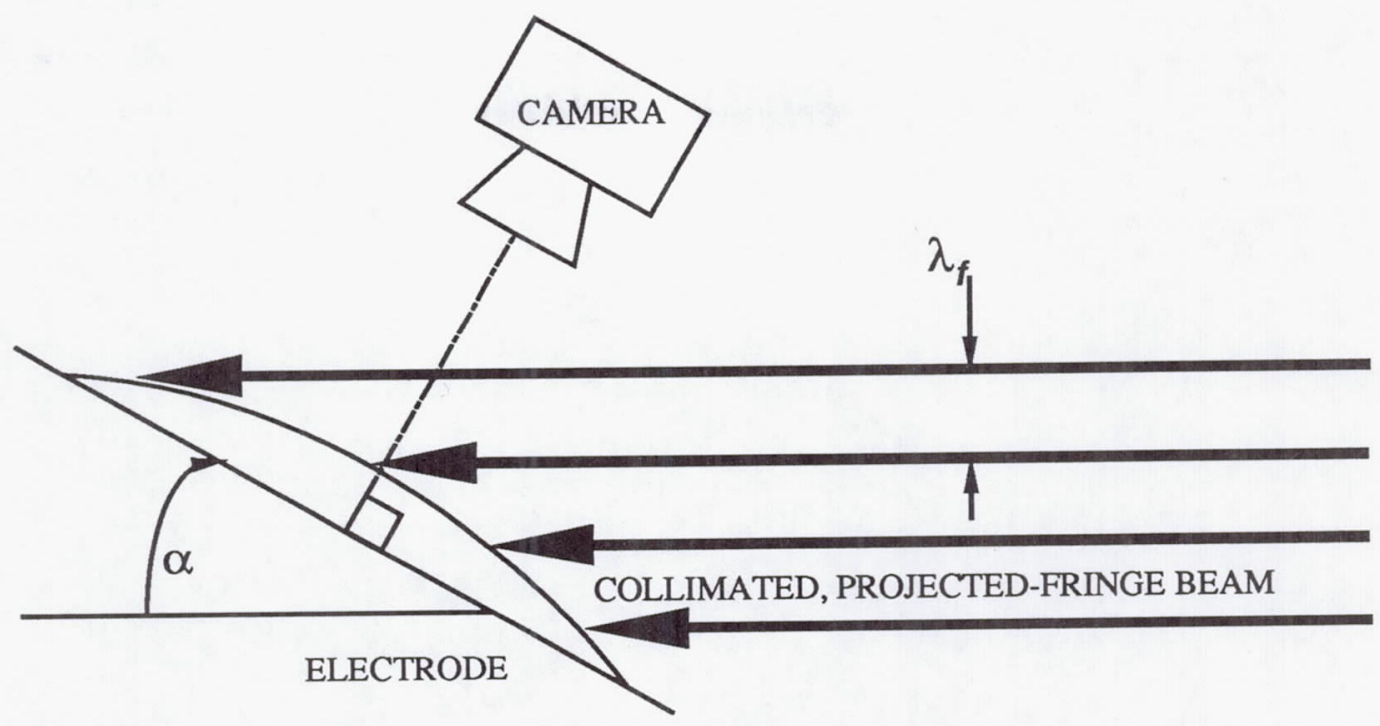

Figure 2. - Geometry for phase map analysis.

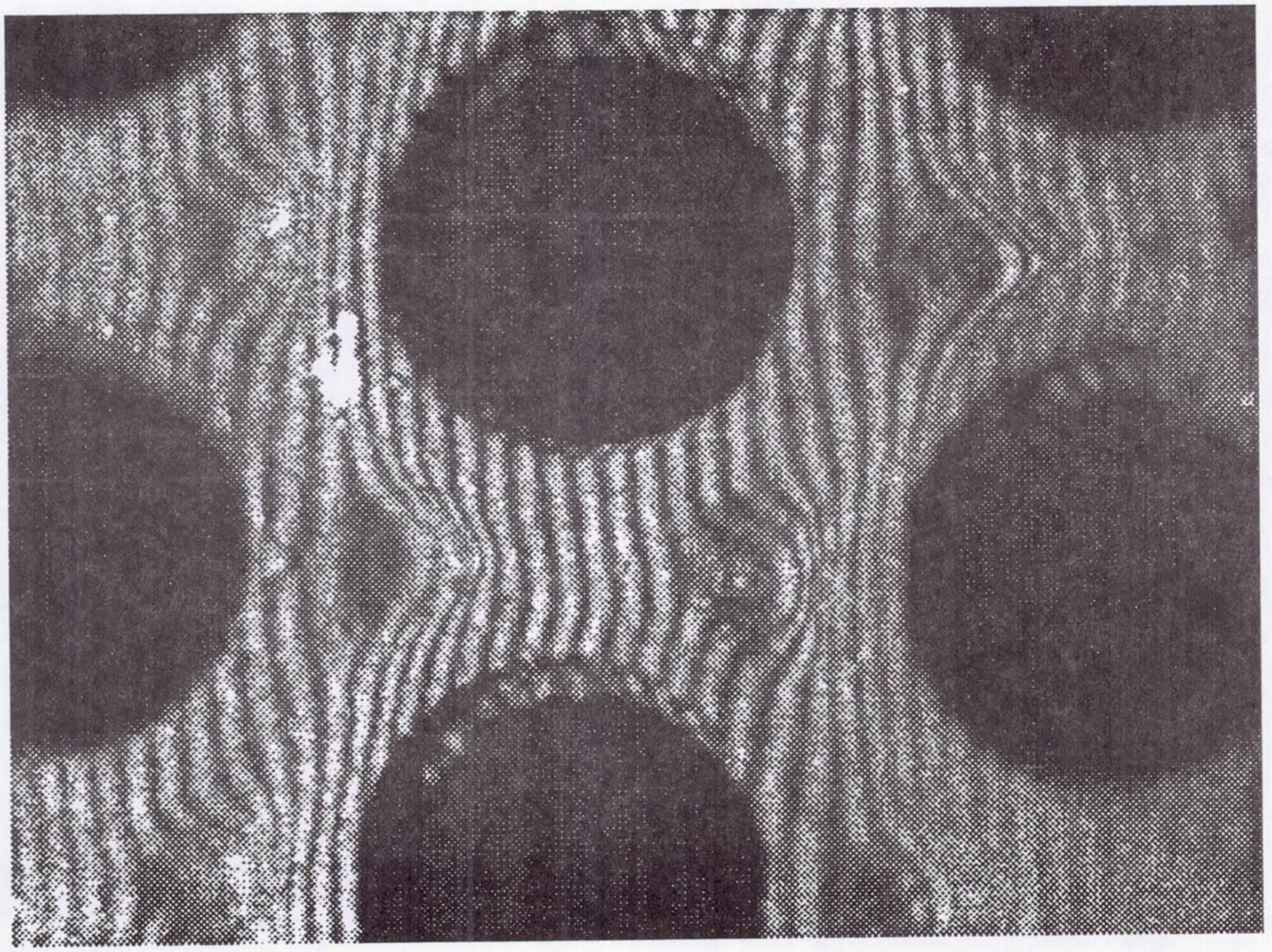

Figure 3. - Accelerator electrode erosion pits with projected fringes. 


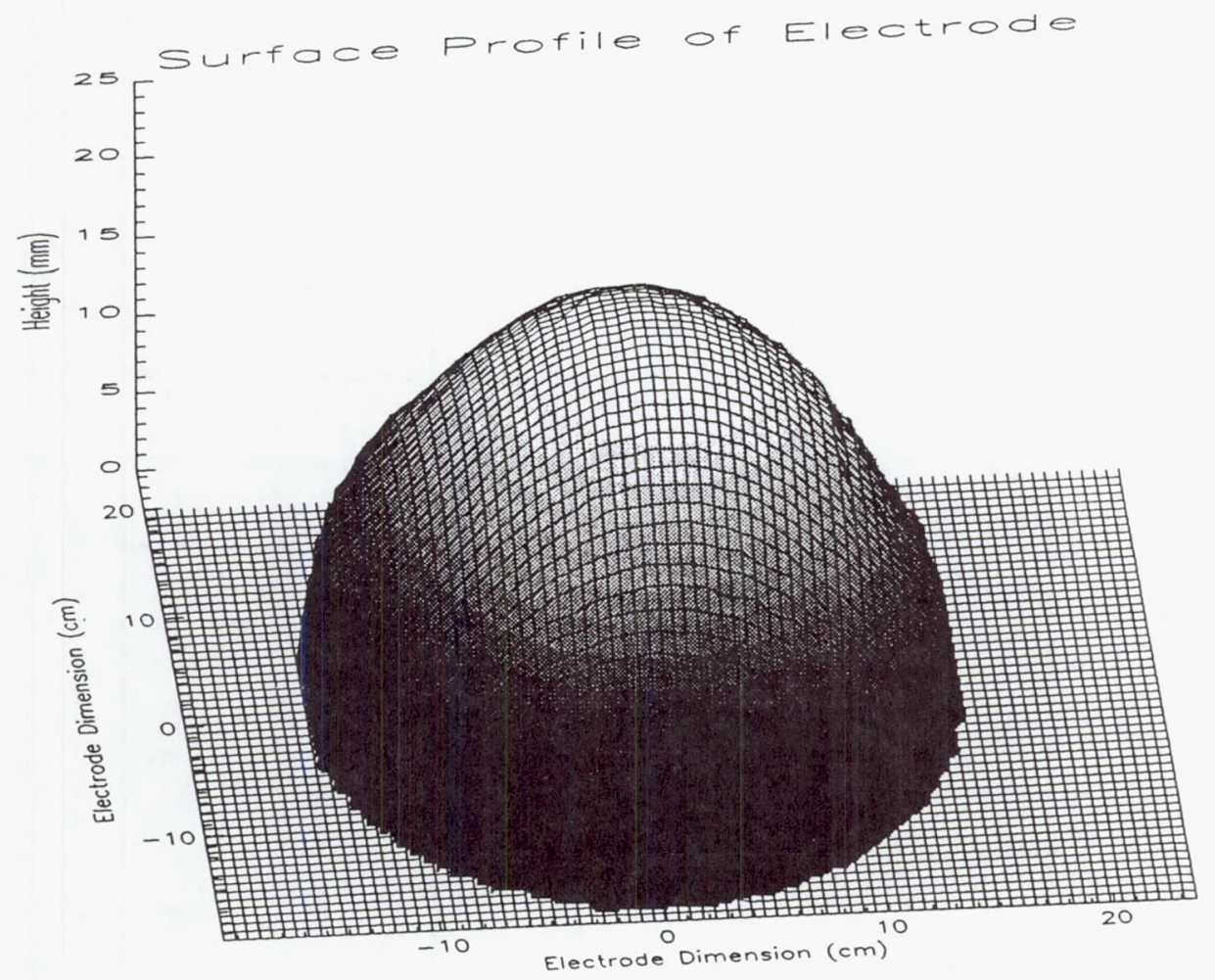

Figure 4. - Full electrode profile.

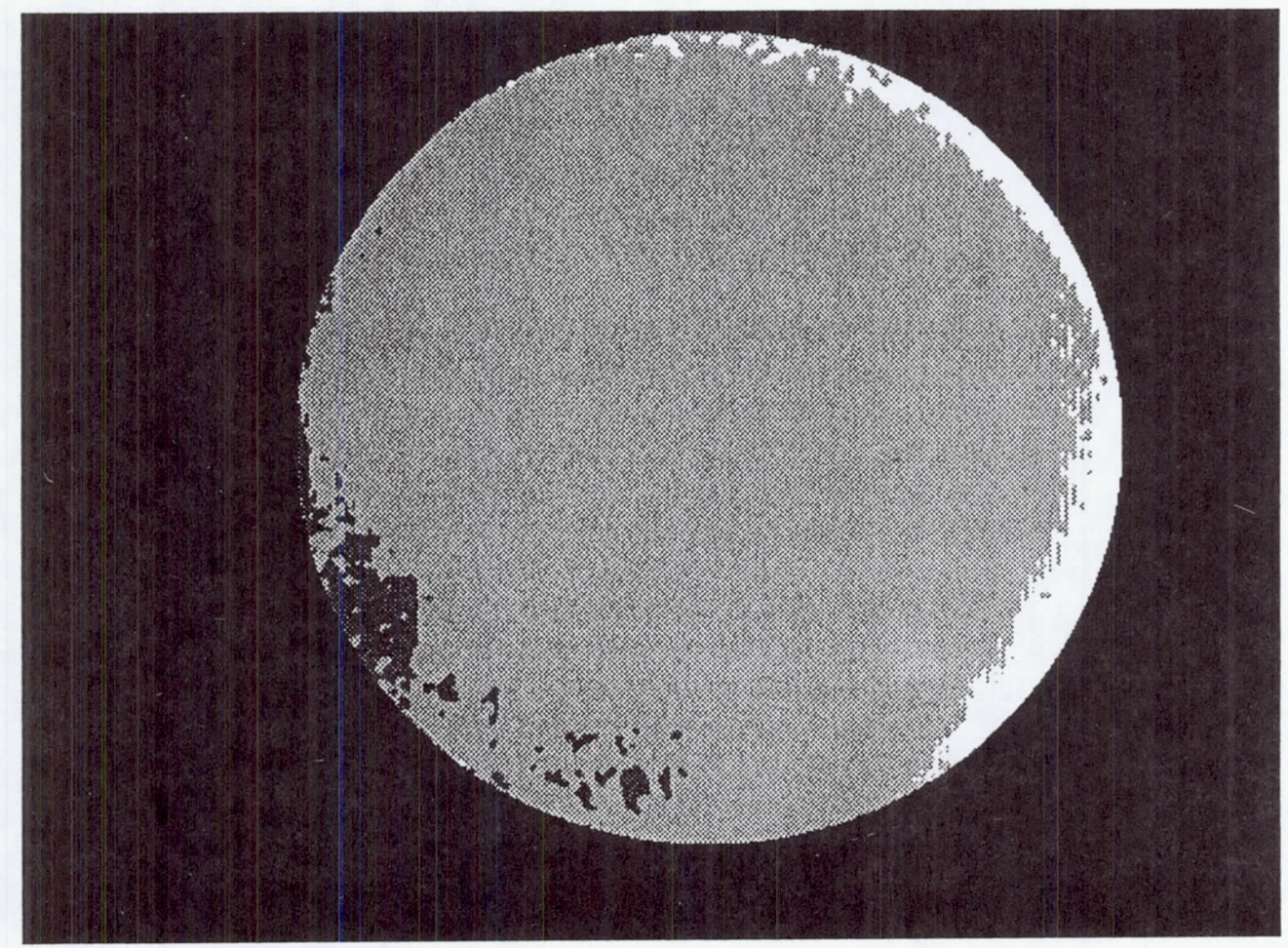

Figure 5. - Deviation of the electrode shape from spherical. Light gray regions are within $2 \mathrm{~mm}$ of spherical, white is high, and black is low. 


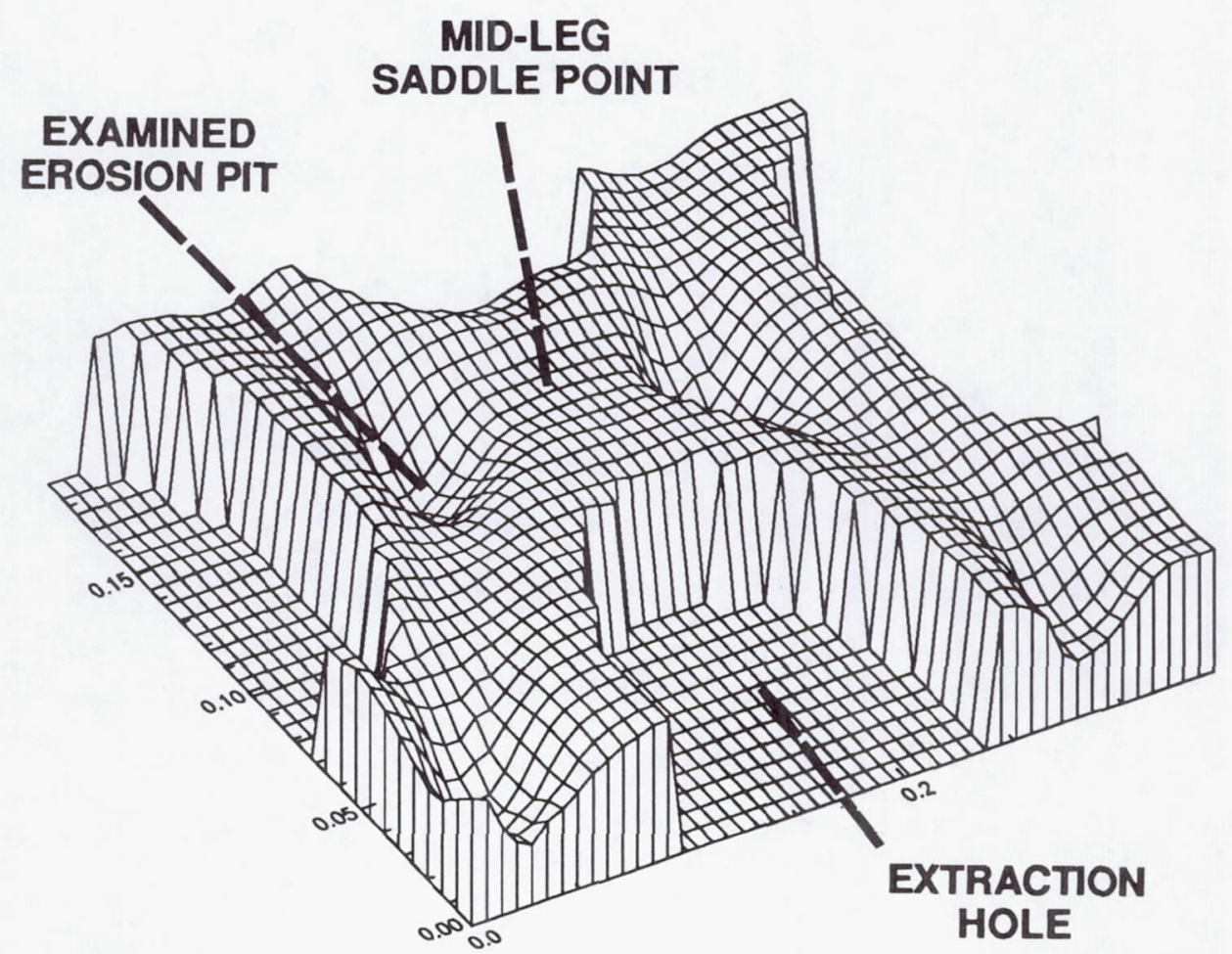

FIGURE 6. - CHARACTERISTIC EROSION PATTERN BETWEEN FOUR HOLES.

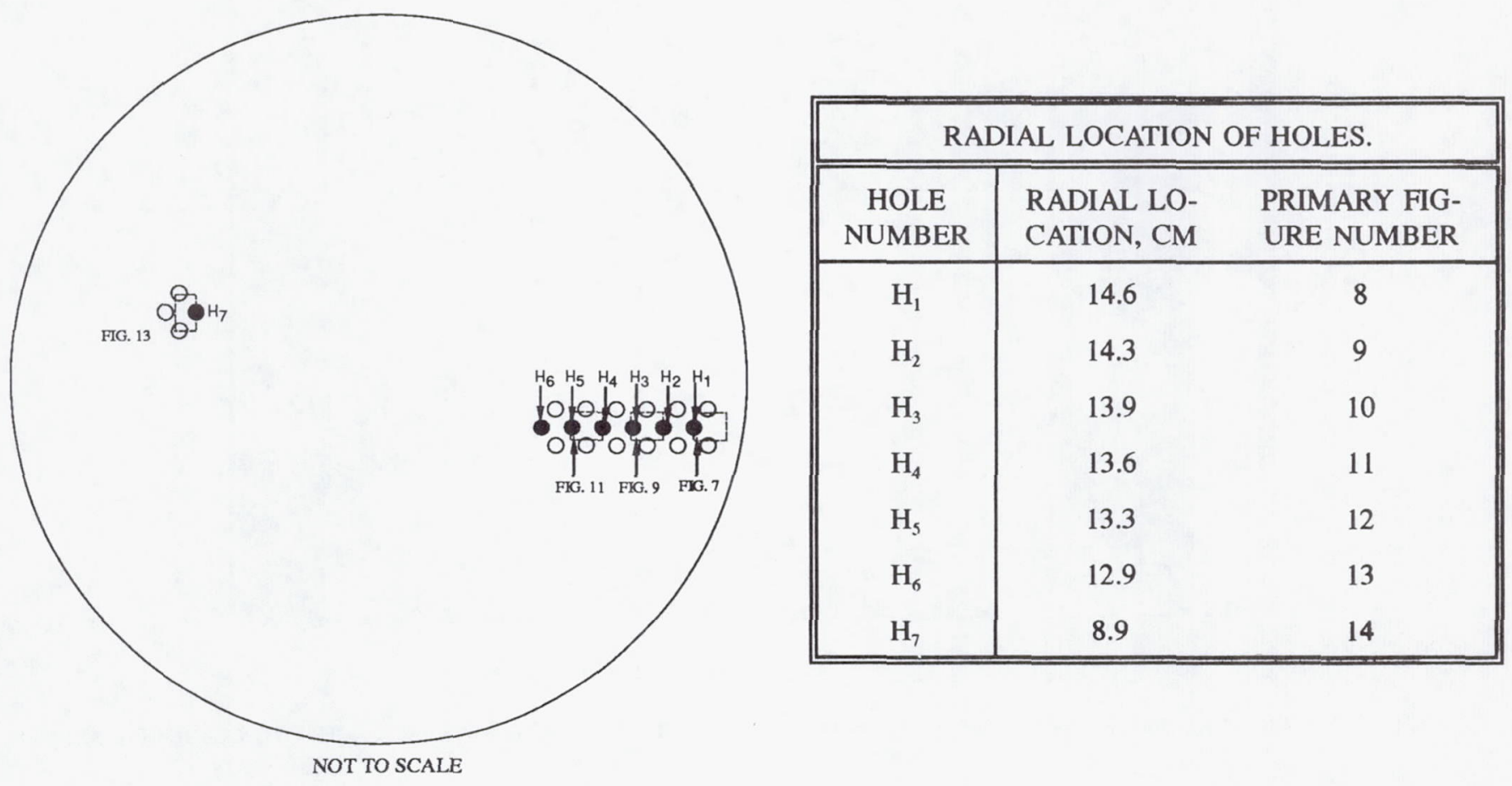

FIGURE 7. - LOCATIONS OF INSPECTED HOLES. 


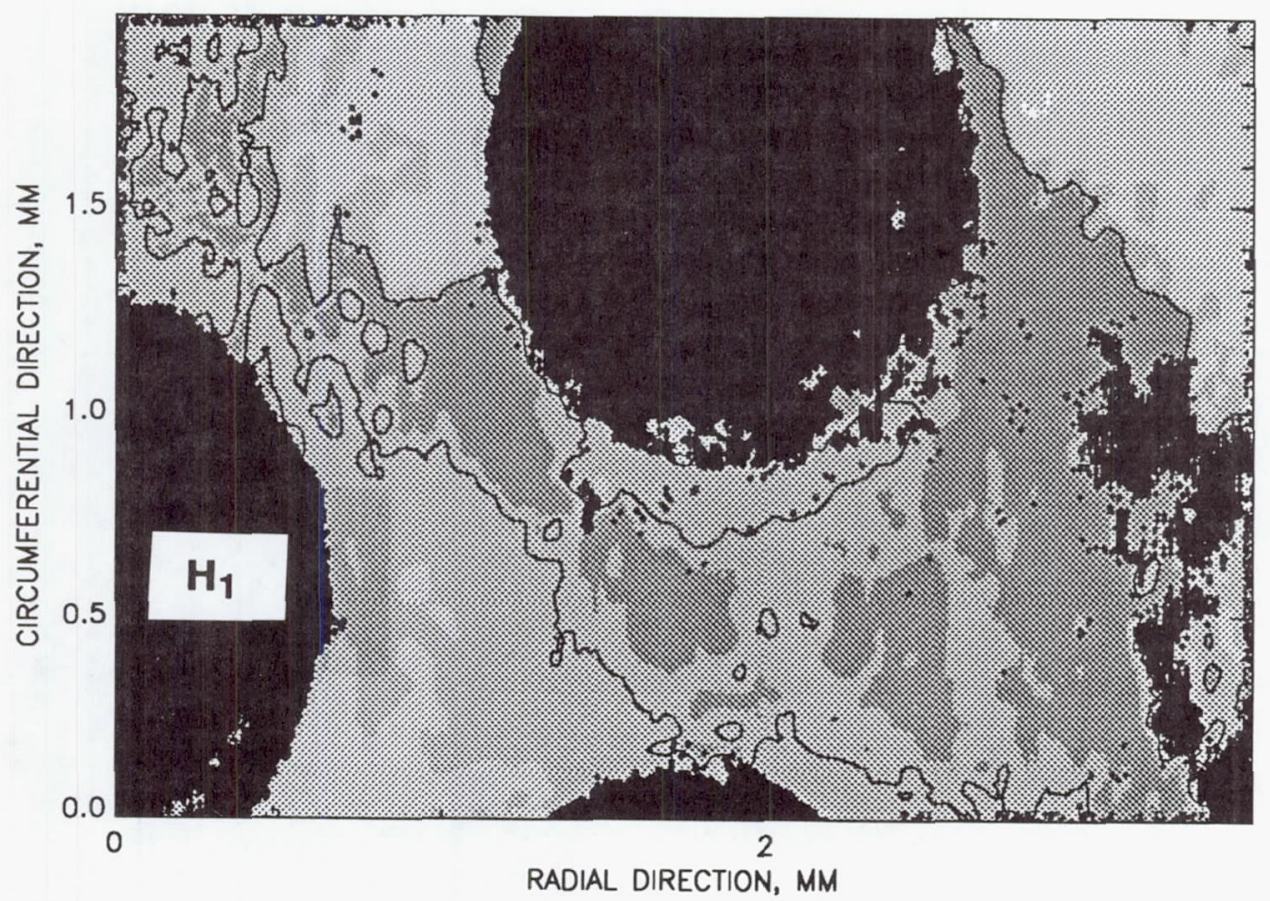

FIGURE 8. - PERIFERAL EROSION PATTERN NEAR HOLE, H1. WHITE SURFACES ARE HIGH, BLACK ARE LOW. CONTOUR LINES ARE SPACED EVERY 100 MICRONS.

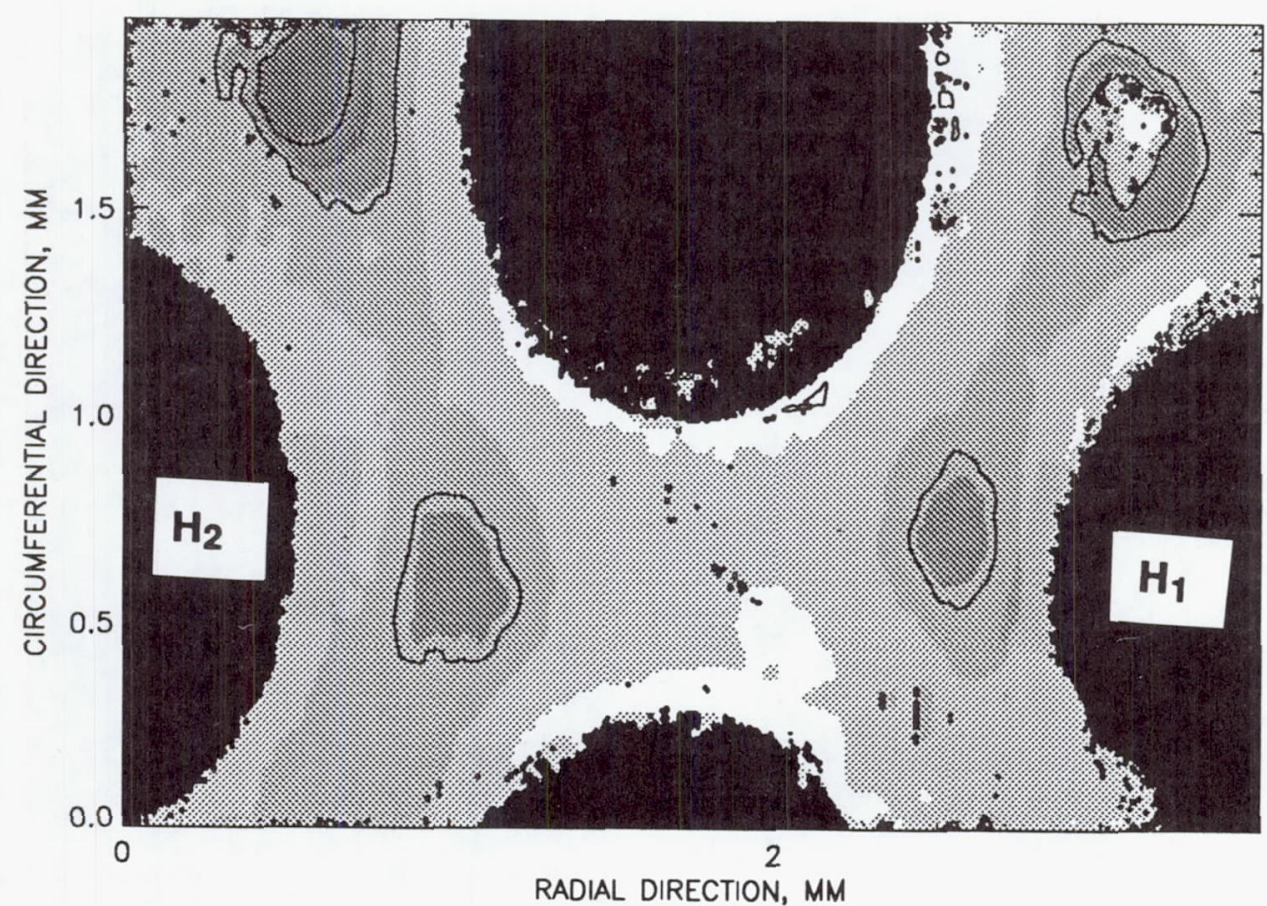

FIGURE 9. - EROSION PATTERN BETWEEN HOLES H1 AND H2. WHITE SURFACES ARE HIGH, BLACK ARE LOW. CONTOUR LINES ARE SPACED EVERY 100 MICRONS. 


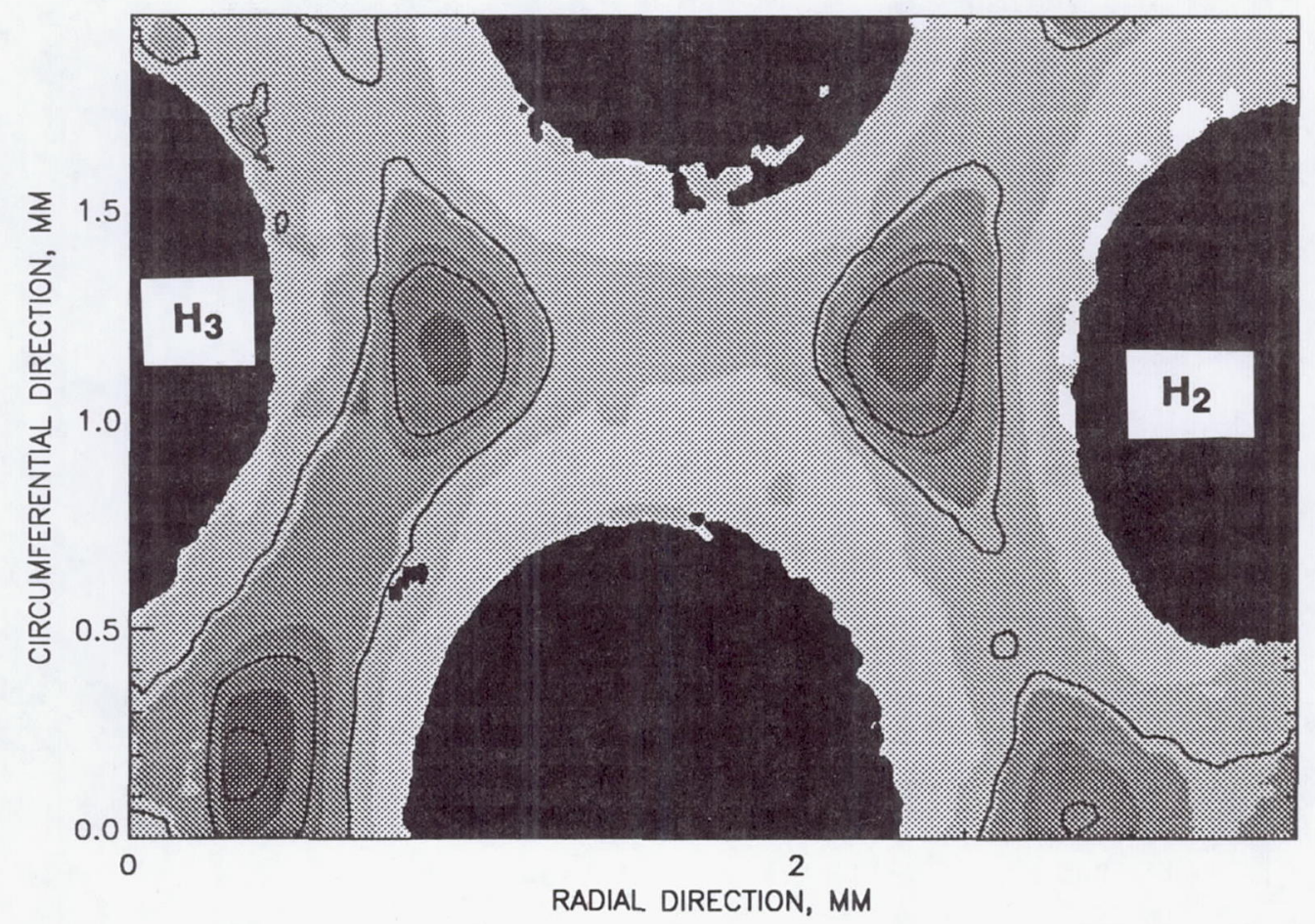

FIGURE 10. - EROSION PATTERN BETWEEN HOLES H2 AND H3. LIGHT SURFACES ARE HIGHER THAN THE DARK. THE CONTOUR LINES ARE 100 MICRONS APART.

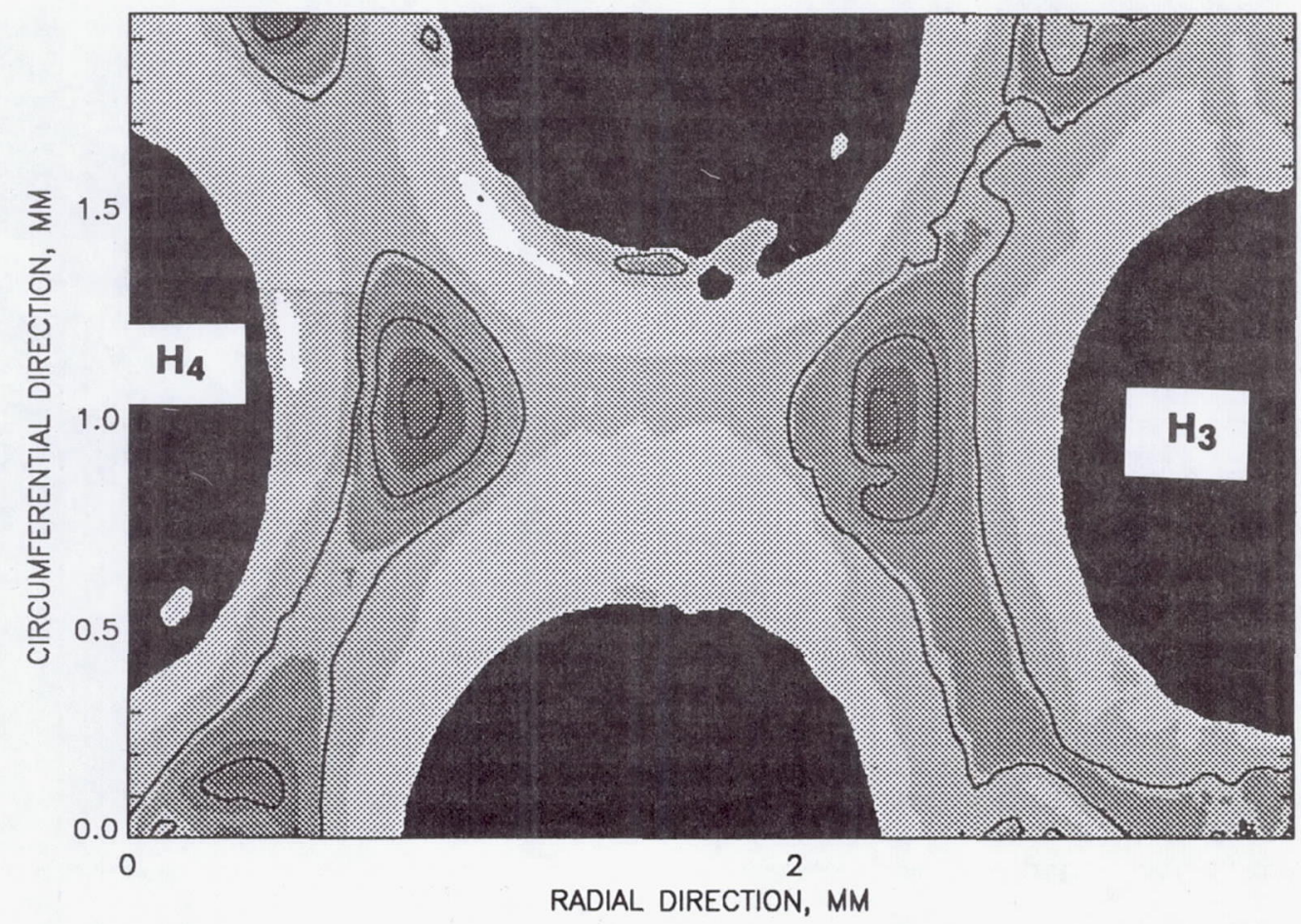

FIGURE 11. - EROSION PATTERN BETWEEN HOLES H3 AND H4. LIGHT SURFACES ARE HIGHER THAN THE DARK. THE CONTOUR LINES ARE 100 MICRONS APART. 


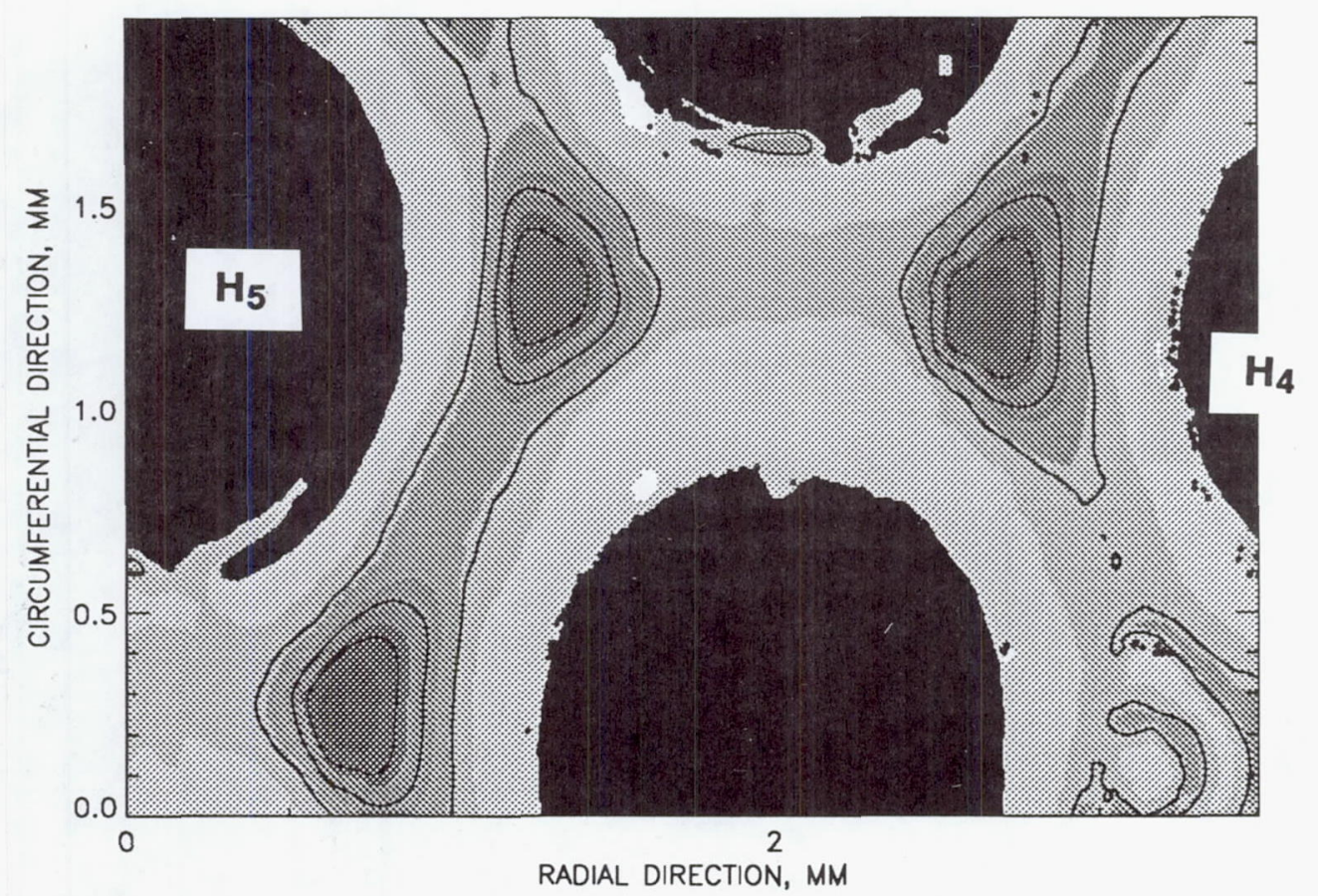

FIGURE 12. - EROSION PATTERN BETWEEN HOLES H4 AND H5. LIGHT SURFACES ARE HIGHER THAN THE DARK. THE CONTOUR LINES ARE 100 MICRONS APART.

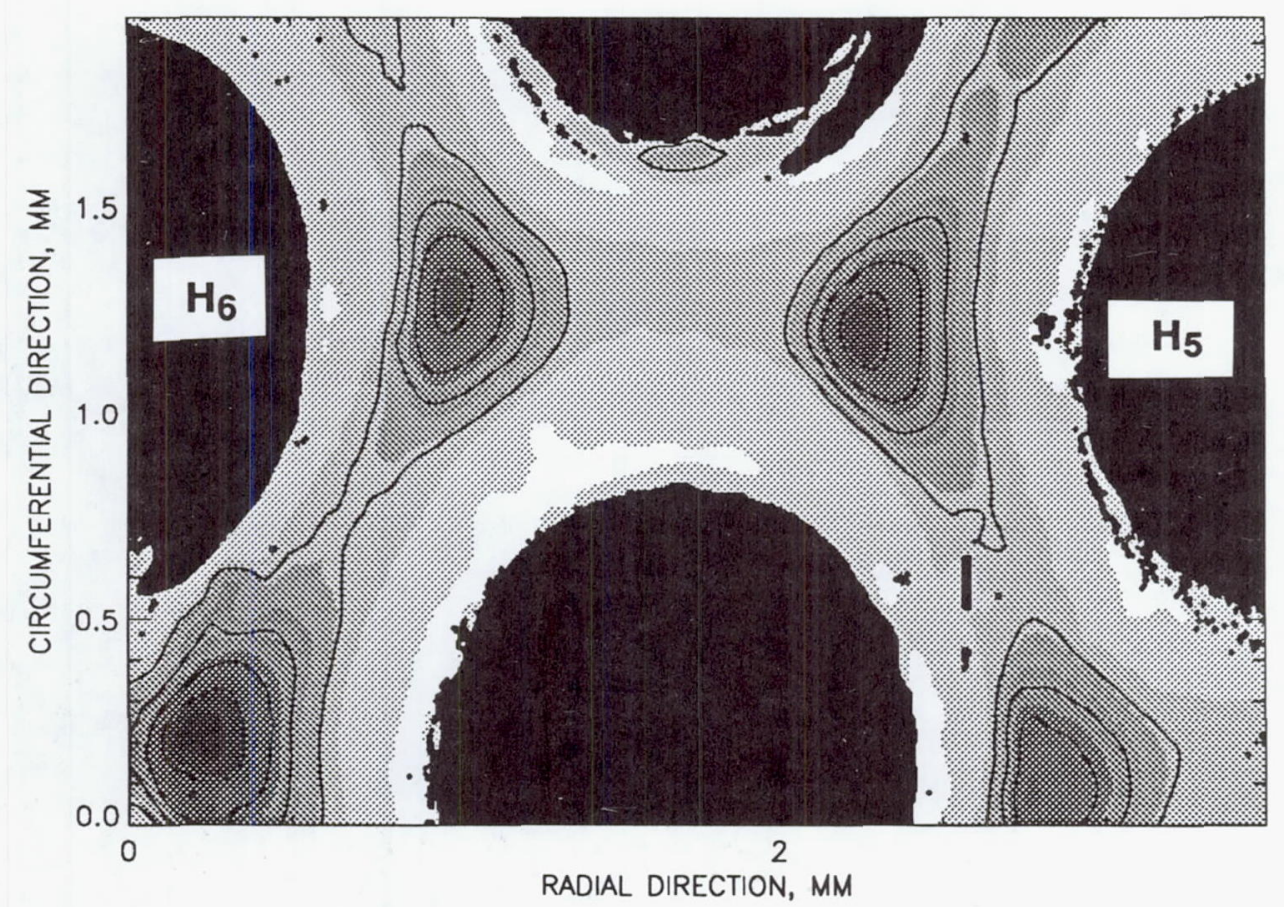

FIGURE 13. - EROSION PATTERN BETWEEN HOLES H5 AND H6. LIGHT SURFACES ARE HIGHER THAN THE DARK. THE CONTOUR LINES ARE 100 MICRONS APART. 


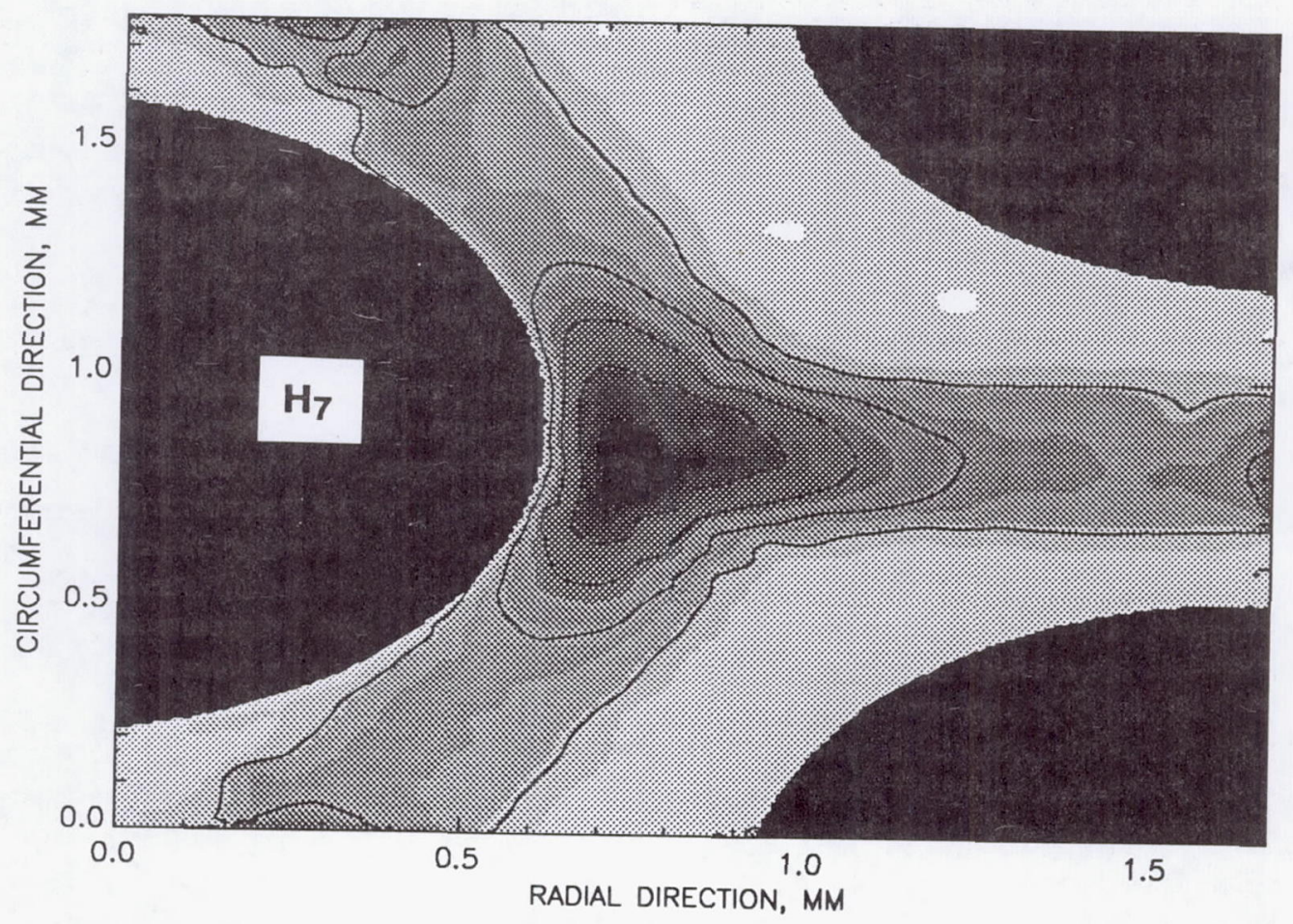

FIGURE 14. - EROSION NEAR HOLE H7, SHOWING A PIT ERODED COMPLETELY THROUGH THE ELECTRODE. LIGHT SURFACES ARE HIGHER THAN THE DARK. THE CONTOUR LINES ARE 100 MICRONS APART. 
Public reporting burden for this collection of information is estimated to average 1 hour per response, including the time for reviewing instructions, searching existing data sources, gathering and maintaining the data needed, and completing and reviewing the collection of information. Send comments regarding this burden estimate or any other aspect of this collection of information, including suggestions for reducing this burden, to Washington Headquarters Services, Directorate for information Operations and Reports, 1215 Jefferson Davis Highway, Suite 1204, Arlington, VA 22202-4302, and to the Office of Management and Budget, Paperwork Reduction Project (0704-0188), Washington, DC 20503.

1. AGENCY USE ONLY (Leave blank) 2. REPORT DATE 3. REPORT TYPE AND DATES COVERED

Technical Memorandum

4. TITLE AND SUBTITLE

Laser Interferometric Measurement of Ion Electrode Shape and Charge Exchange Erosion

6. AUTHOR(S)

Gregory S. MacRae and Carolyn R. Mercer
5. FUNDING NUMBERS

WU - 506- $42-31$

\section{PERFORMING ORGANIZATION NAME(S) AND ADDRESS(ES)}

8. PERFORMING ORGANIZATION REPORT NUMBER

National Aeronautics and Space Administration Lewis Research Center

Cleveland, Ohio 44135-3191

E- 6454

9. SPONSORING/MONITORING AGENCY NAMES(S) AND ADDRESS(ES)

10. SPONSORING/MONITORING AGENCY REPORT NUMBER

National Aeronautics and Space Administration

Washington, D.C. 20546-0001

NASA TM -105165

11. SUPPLEMENTARY NOTES

Prepared for the 27th Joint Propulsion Conference cosponsored by AIAA, SAE, ASME, and ASEE, Sacramento, California, June 24 - 27, 1991. Responsible person, Gregory S. MacRae, (216) 433 - 2452.

12a. DISTRIBUTION/AVAILABILITY STATEMENT

12b. DISTRIBUTION CODE

Unclassified - Unlimited

Subject Categories 20 and 35

\section{ABSTRACT (Maximum 200 words)}

A novel, projected fringe profilometry system was applied to surface contour measurements of an accelerator electrode from an ion thruster. The system permitted noncontact, nondestructive evaluation of the fine and gross structure of the electrode. A three-dimensional surface map of a dished electrode was generated without altering the electrode surface. The same system was used to examine charge exchange erosion pits near the periphery of the electrode to determine the depth, location, and volume of material lost. This electro-optical measurement system allowed rapid, nondestructive, digital data acquisition coupled with automated computer data-processing. In addition, variable sensitivity allowed both coarse and fine measurements of objects having various surface finishes.

\section{SUBJECT TERMS}

Profilometers; Laser applications; Ion engines; Ion sources; Erosion; Fiber optics; Laser interferometry

17. SECURITY CLASSIFICATION
OF REPORT
Unclassified

18. SECURITY CLASSIFICATION OF THIS PAGE Unclassified
19. SECURITY CLASSIFICATION OF ABSTRACT Unclassified 

National Aeronautics and

Space Administration

Lewis Research Center

21000 Brookpark Rd.

Cleveland, $\mathrm{OH}$ 44135-3191

Official Business

Penalty for Private Use $\$ 300$ 